\title{
Measurement of Degree of Compaction of Fine-Grained Soil Subgrade Using Light Dynamic Penetrometer
}

\author{
Junhui Zhang $\mathbb{D},{ }^{1}$ Yongsheng Yao $\mathbb{D}^{\mathbb{D}},{ }^{1}$ Jianlong Zheng, ${ }^{1}$ Xiangqun Huang, ${ }^{1,2}$ \\ and Tian $\operatorname{Lan}^{1}$ \\ ${ }^{1}$ National Engineering Laboratory of Highway Maintenance Technology, Changsha University of Science \& Technology, \\ Changsha 410114, China \\ ${ }^{2}$ Hunan Communications Research Institute, Changsha 410007, China
}

Correspondence should be addressed to Yongsheng Yao; yaoyongsheng23@163.com

Received 27 February 2018; Revised 29 April 2018; Accepted 26 May 2018; Published 12 July 2018

Academic Editor: Qiang Tang

Copyright ( $(2018$ Junhui Zhang et al. This is an open access article distributed under the Creative Commons Attribution License, which permits unrestricted use, distribution, and reproduction in any medium, provided the original work is properly cited.

To determine the degree of compaction of subgrades filled with fine-grained soil, the compaction test and light dynamic penetrometer (LDP) test were carried out for low liquid-limit clay samples with different water contents in laboratory. Then, a prediction equation of the penetration ratio (PR) defined as the depth per drop of the hammer of LDP, degree of compaction $(K)$, and water content $(\omega)$ was built. After that, the existing fine-grained soil subgrades on LDP-based field tests were excavated. The on-site PR values, water contents, and degrees of compaction of slopes were obtained. The estimated degrees of compaction using the prediction equation were compared with measured values of the degree of compaction in field. The results show that there is good consistency between them, and an error within 3.5\% was obtained. In addition, the water content should be determined firstly while using the prediction equation which is proposed in this study. Therefore, a numerical method of the water content of a subgrade was developed, and the predicted and measured water contents were compared, which shows a relatively high relativity. Then, the degree of compaction of fine-grained soil subgrades can be calculated according to the predicting equation, which involves the penetration ratio (PR) and the numerically calculated water content as input instead of the measured value in the field.

\section{Introduction}

In civil engineering, the investigation of the strength and integrity of every highway subgrade becomes necessary to optimize pavement structural performance and safety [1]. The degree of compaction is a significant index of investigation to achieve the goal of in situ quality control/quality assurance of granular pavement layers (subgrade, subbase, and base) [2-4]. If the results of investigation do not meet the requirements of compaction in design, the carrying capacity of the subgrade would be lower and then some distresses would occur such as the settlement of the subgrade and the cracking of pavement [5]. Traditionally, one of the activities during the subgrade investigation is determination of degree of compaction with different field and laboratory tests such as the sand-cone method [6] and cutting ring method [7, 8]. Although these evaluation methods are the best and reliable, they have relatively complicated steps and take much time to have the end result [9]. In addition, the soil samples in these methods need to be cored or excavated on the subgrade which is destructive and can have significant impact on pavement performance [10]. To overcome these shortcomings, many nondestructive and time-saving determination methods and equipment have been developed [11-13].

As a nondestructive, effective, fast, and reliable testing method, the dynamic cone penetrometer (DCP) has been introduced as a criterion for testing the foundation capacity in specifications of American Association of State Highway and Transportation Officials (AASHTO) and South Africa [14]. This device provides continuous and uninterrupted stratigraphic data when its cone probe is driven into soil along the vertical depth. The data obtained from the DCP have got a strong theoretical acceptance and can be used to comprehensively assess the foundation soil. The application of the DCP 

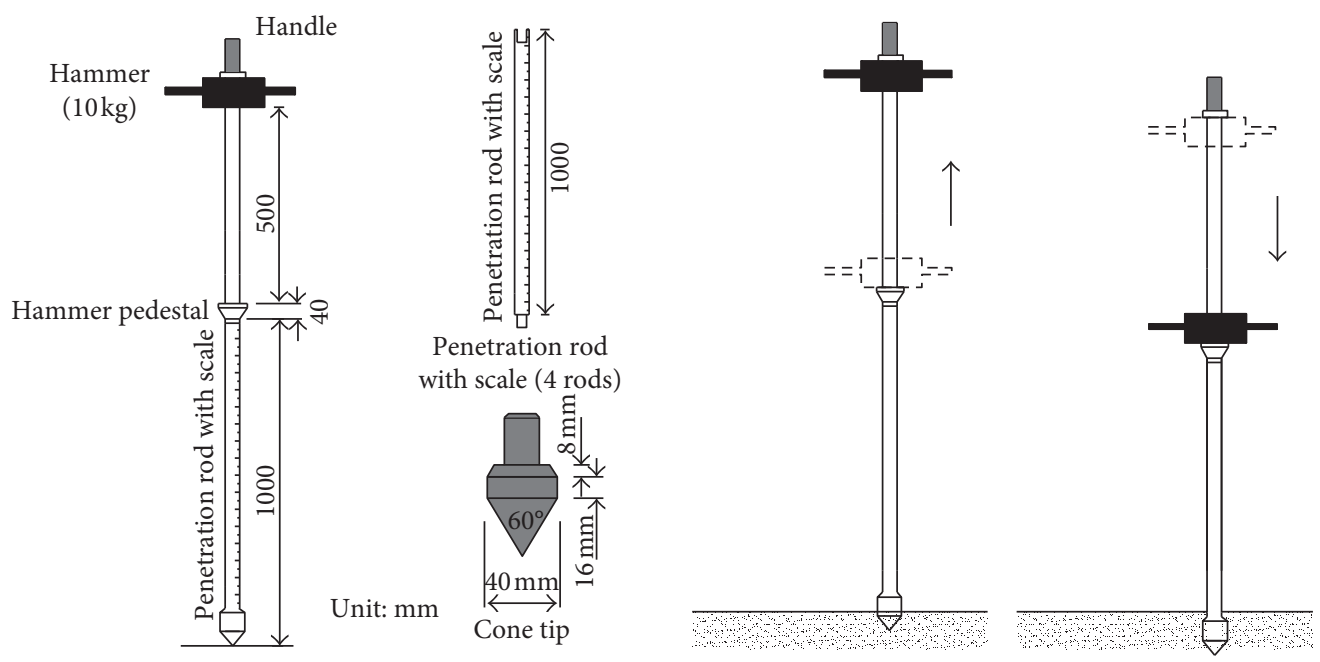

FIGURE 1: Diagram of the LDP device and principal.

was further investigated by previous researchers. Siekmeier et al. [15], George et al. [16], and Mukabi [17] built the empirical formula combining the penetration ratio $(\mathrm{PR})$ of the DCP with the elasticity modulus and California bearing ratio (CBR). Mohammadi et al. [18], Alghamdi [19], Emre et al. [20], and Yang et al. [21] have gained some beneficial achievements to evaluate the subgrade compactness by the DCP, and the correlation between the degree of compaction, penetration ratio, and water content was established. The advantage of using the DCP is testing the soil properties in its natural density and moisture content state. These applications of the theory and method of the DCP have been accepted for different soils, and they provide a way to the empirical correlations based on the statistical analyses of field tests and soil properties.

The light dynamic penetrometer (LDP) is also a nondestructive method to evaluate the performance of the soil layer, which has a similar working principle to the DCP's. Compared to the DCP, its hammer is lighter and the drop distance is shorter, which is convenient and fast for the field testing of subgrade using the LDP instead of the DCP. Therefore, the objective of this paper is to test the degree of compaction of the fine-grained soil subgrade using the LDP. First, the principles and steps of the LDP-based test were introduced. The compaction and LDP tests of a typical low liquid-limit clay were conducted in the laboratory, and a quadratic predicting equation between the degree of compaction $(K)$, the penetration ratio $(\mathrm{PR})$, and the water content $(\omega)$ was established. Then, the validity of this equation was verified by the field tests of fine-grained soil subgrades. Finally, a numerical method for calculating the water content of subgrades was put forward and verified. Thus, the degree of compaction of fine-grained soil subgrades can be calculated according to the quadratic predicting equation, which uses the penetration ratio (PR) and the numerically calculated water content instead of the measured value in the field.

\section{Device and Testing Method of LDP}

The light dynamic penetrometer (LDP), a small-sized portable foundation soil in situ test penetrometer, consists of a hammer (10 kg in weight and $500 \mathrm{~mm}$ in drop distance), a penetration rod (1,000 $\mathrm{mm}$ long and a total of 4 rods), and a conical head ( $40 \mathrm{~mm}$ in diameter and $60^{\circ}$ at the conical tip), as shown in Figure 1. When a field test is conducted using the LDP, the depth and drops of the hammer of the LDP are recorded when the cone tip is driven into soils by the hammer. The penetration ratio (PR), defined as the depth per drop of the hammer, can reflect the properties of soil layers.

When a test using the LDP is conducted, the following procedure should be carried out:

(1) The testing site should be flat, and a record book also should be prepared.

(2) Cone tip and penetration rod with scale should be assembled and connected. The penetration rod should always be perpendicular to the ground surface when the test is in progress.

(3) When the test is in progress, the penetration rod should be held on by one tester. The hammer should be lifted and released along the penetration rod. At the same time, the penetration frequency and depth are needed to be recorded.

\section{LDP-Based Lab Test and Prediction of Degree of Compaction}

3.1. LDP-Based Lab Test. The soil samples were taken from the Nanchang-Zhangshu expressway widening project in Jiangxi Province. The liquid limit, plastic limit, optimum moisture content, maximum dry density, and particle size analysis were conducted for soil classification and basic properties. Their liquid limit and plastic limit are $35.8 \%$ and $22.8 \%$, respectively. According to the compaction test, the optimum moisture content and maximum dry density are $13.0 \%$ and $1.954 \mathrm{~g} / \mathrm{cm}^{3}$, respectively. The particle size analysis shows that $0.075 \mathrm{~mm}$ passing percentage of the soil samples is $82.2 \%$. Therefore, the soil sample was categorized as a low liquid-limit clay according to the standard of Test 


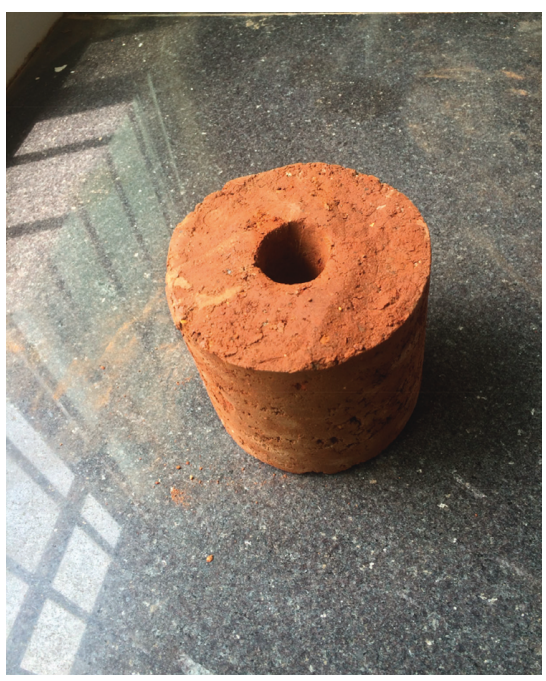

(a)

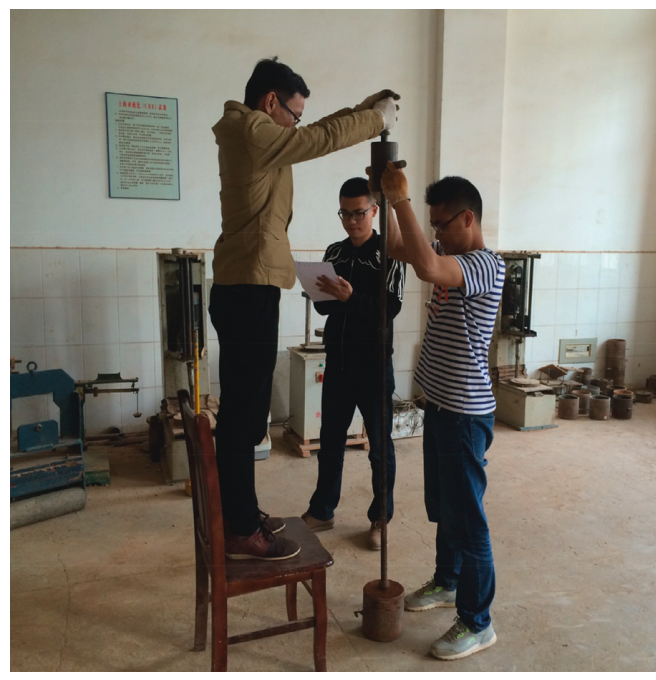

(b)

Figure 2: LDP-based lab test.

Methods of Soils for Highway Engineering (JTG E40-2007) in China.

In order to study the influence of water content on the PR measured by the LDP, different soil specimens with 5 initial water contents and 5 dry densities were prepared. The water contents of soil samples were set to $9 \%, 13 \%, 16 \%$, $19 \%$, and $23 \%$, covering the possible moisture content range of subgrade soils in China. The degrees of compaction of the subgrade are $96 \%$ and $93 \%$, respectively, according to the requirements of the current specification in China. In order to improve the accuracy of the LDP-based test, the degrees of compaction of $82 \%, 86 \%, 90 \%, 94 \%$, and $98 \%$ of soil samples were selected. The samples of $152 \mathrm{~mm} \times 220 \mathrm{~mm}$ (diameter $\times$ height) were prepared by the static pressure method by 5 layers, as shown in Figure 2. The relationships between the water content and PR with different degrees of compaction were curved in Figure 3. It can be seen in Figure 3 that the minimum PR value is found nearby the optimum water content for the same degree of compaction, and the PR values decrease with the increasing degree of compaction values for the same water content. As mentioned above, the penetration ratio $(\mathrm{PR})$ of the LDP can reflect the density properties of soil layers. Thus, the relationship between the $\mathrm{PR}$, degree of compaction $(K)$, and water content $(\omega)$ of soils can be built according to the results of the LDP [18-21], as shown in the following equation:

$K=0.1538 \omega^{2}-3.9713 \omega-1.1284 \mathrm{PR}+121.3193\left(R^{2}=0.897\right)$,

where $K$ is the degree of compaction of soil (\%), PR is the penetration ratio ( $\mathrm{mm} / \mathrm{drop})$, and $\omega$ is the water content of soil (\%).

3.2. LDP-Based Field Test. A typical section of $\mathrm{K} 24+600$, where the soil samples were taken from, was selected. The light dynamic penetrometer (LDP) tests were carried out

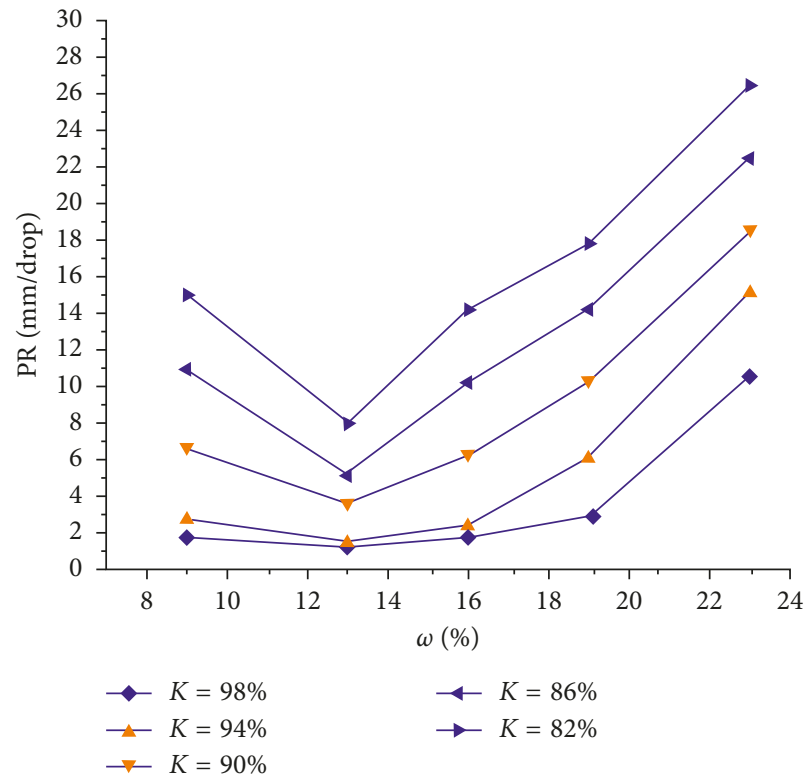

Figure 3: PR- $\omega$ under different compaction conditions.

from the top of 96 zone (i.e., the degree of compaction of 96\%), 94 zone, and 93 zone of the existing subgrade, with a penetrating depth of $360 \mathrm{~cm}$, as shown in Figure 4. The test data were recorded for every $20 \mathrm{~cm}$ penetration depth.

Figure 5 shows the PR values of different testing programs. It can be seen from Figure 5 that the PR values gradually increase with the increasing depth, which indicates that the degree of compaction of subgrades' slope soil gradually decreases with the increasing depth. The PR value is about $13 \mathrm{~mm}$ per stroke of the hammer within the depth of $100 \mathrm{~cm}$ of the subgrade slope and distributes relatively uniformly. The reason is that the LDP-based field test was conducted in summer, and the water contents of slope surface were relatively low. The PR values increase gradually and are $14 \mathrm{~mm}$ to $20 \mathrm{~mm}$ per hammering within the depth of 


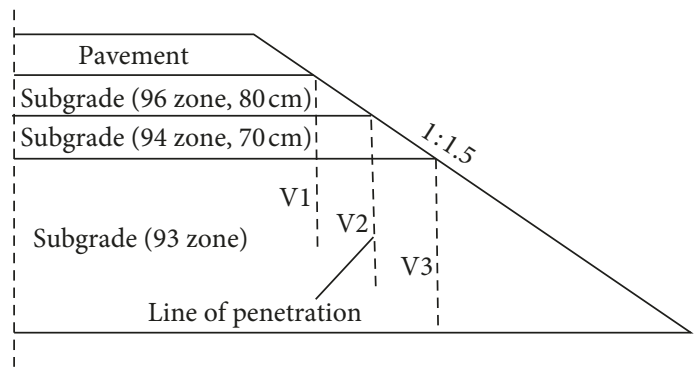

(a)

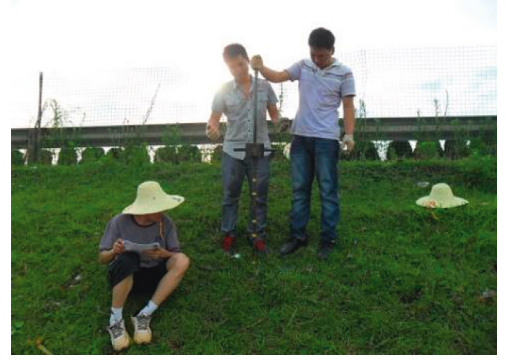

(b)

Figure 4: (a) Diagram of LDP-based test. (b) LDP-based field test.

$100 \mathrm{~cm}$ to $360 \mathrm{~cm}$. In addition, it can be seen from Figure 5 that though V1, V2, and V3 started from the top of different zones, their PR values are almost the same within the depth of $100 \mathrm{~cm}$. It shows that there is no obvious difference in properties of the subgrade within this scope in spite of the fact that their initial degrees of compaction are different. Also, Figure 5 shows that the PR values of V3 section are larger than those of the other two sections, which indicates that the water contents of the bottom subgrade are larger than those of the top subgrade.

\subsection{Measurement of Degree of Compaction and Water Con-} tent of Subgrade Slope. To investigate the changes of the degree of compaction and water content of the subgrade slope of $\mathrm{K} 24+600$, it was excavated manually to a ditch with a $50 \mathrm{~cm}$ width and a $510 \mathrm{~cm}$ depth along the V1 section. The degree of compaction and water content were measured by the cutting ring test method on the horizontal planes with a vertical distance of $20 \mathrm{~cm}$. The lowest horizontal plane is on the bottom of the ditch. For every horizontal plane, two soil samples with a distance of $20 \mathrm{~cm}$ in the longitudinal direction (parallel to the traffic direction) were selected, as shown in Figure 6. Their average values were taken as the final values for this location.

Figure 7 shows the measured water contents and degrees of compaction. It can be seen in Figure 7(a) that the water content increases gradually with the increasing depth and becomes relatively stable below the depth of $200 \mathrm{~cm}$. The water contents are between $18 \%$ and $27 \%$ within the depth of $200 \mathrm{~cm}$ and $21 \%$ to $27 \%$ below the depth of $200 \mathrm{~cm}$. This is because the water content for the top depth is controlled by the climate and that for the bottom depth is controlled by the ground water. The former changes sharply for different seasons, while the latter is stable with seasonal changes. It can be seen in Figure 7 (b) that the degree of compaction changes sharply from $80 \%$ to $93 \%$ within the depth of $200 \mathrm{~cm}$. For the depth below $200 \mathrm{~cm}$, the degrees of compaction are relatively stable, changing from $82 \%$ to $88 \%$.

3.4. Comparison of Predicted and Measured Degrees of Compaction. The estimated degrees of compaction using (1) and the measured values are shown in Figure 8. It can be seen in Figure 8 that they are relatively consistent. The root mean square errors between the estimated and measured

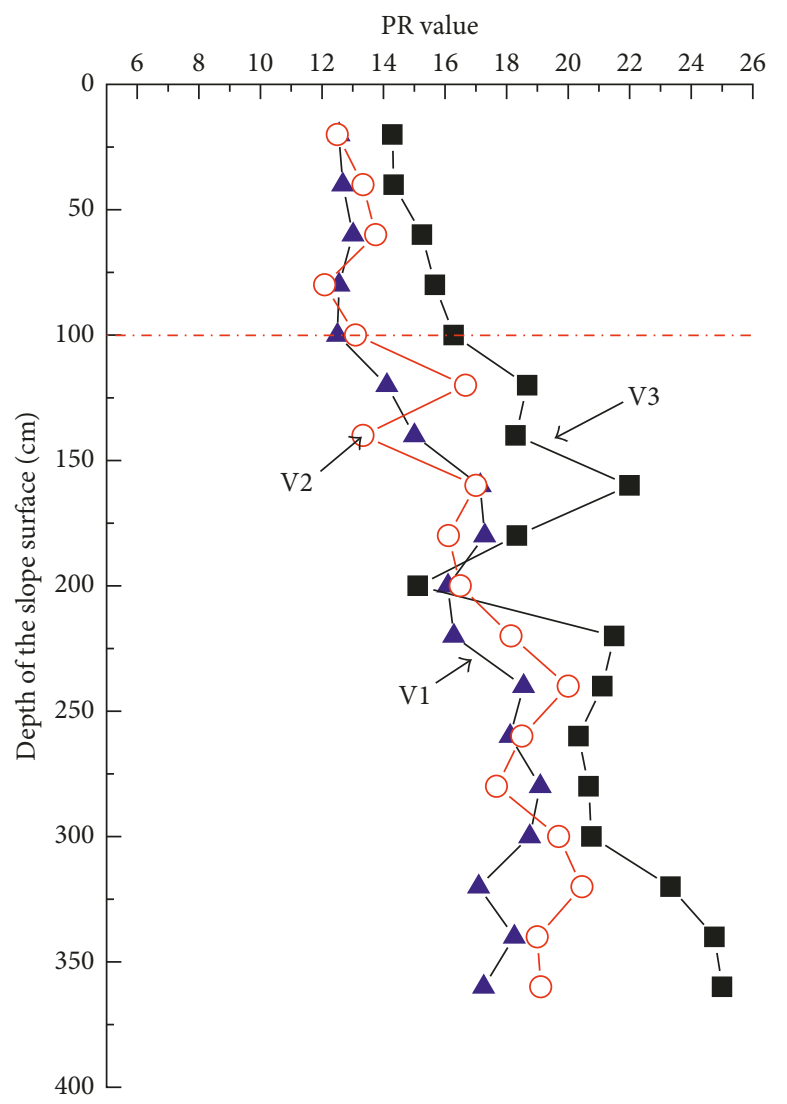

FIGURE 5: PR values for different sections.

degrees of compaction at V1, V2, and V3 vertical sections are $3.44 \%, 3.24 \%$, and $3.31 \%$, respectively, and the average of root mean square errors is $3.33 \%$. Therefore, the differences between the estimated and measured degrees of compaction are acceptable, which means that the predicting equation of degrees of compaction based on the PR and water content has a satisfactory accuracy.

\section{Degree of Compaction according to Numerical Moisture Content}

According to the above research, the degree of compaction of subgrade slope soil at different depths can be calculated based on the PR value and the measured water content. The former can be gained quickly using the LDP, and the latter is 


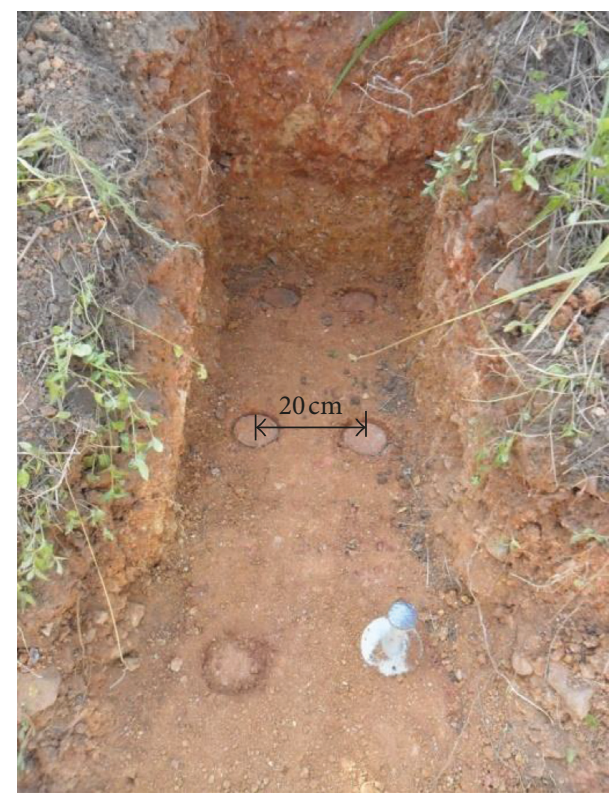

FIgURE 6: Locations of soil samples.

time consuming. Therefore, a rapid method to determine the water content is the key to calculate the degree of compaction using (1). The water content of subgrade slope soil can be calculated using the numerical simulation, which is proved to be rational by some researchers using the GeoStudio software [22-25].

4.1. Test Parameters. This simulation needs some parameters including the hydraulic properties, thermodynamic properties, physiological parameters, and meteorological parameters of soils. All the needed parameters are shown in Table 1. Their values can be referred to the literature [22].

4.2. Calculated and Measured Water Content Values. Then, a numerical modelling of the subgrade slope of K24 +600 was completed according to the method of the literature $[22,26,27]$. Water content was calculated using the parameters mentioned above, and the results of calculated water content values of soil are shown in Figure 9. The measured values for the section of K24+600 are also drawn in Figure 9. It can be seen in Figure 9 that the calculated and measured water contents of V1, V2, and V3 sections show a good coincidence in general. Due to the inhomogeneity of the subgrade and the measured errors, some data are scattered. Besides the discrete points, the root mean square errors between the measured and calculated water contents of V1, V2, and V3 sections are 1.19\%, 1.53\%, and 1.34\%, respectively, and their average value is $1.35 \%$. It shows a relatively high accuracy for engineering practices. Therefore, the water content of the subgrade in different depths can be calculated using the numerical method.

\subsection{Degree of Compaction Based on Calculated and Measured} Water Contents. Furthermore, to investigate the accuracy of the degrees of compaction from (1) using the calculated and

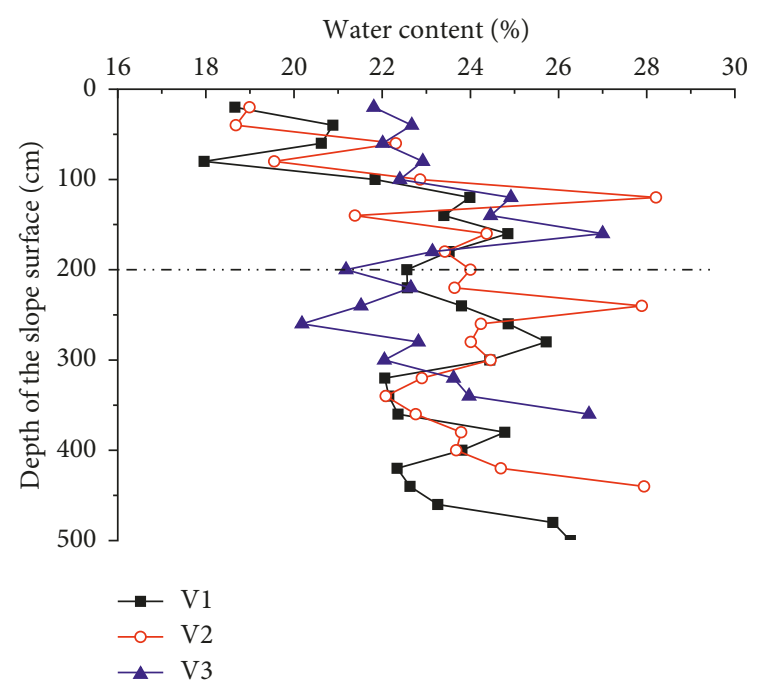

(a)

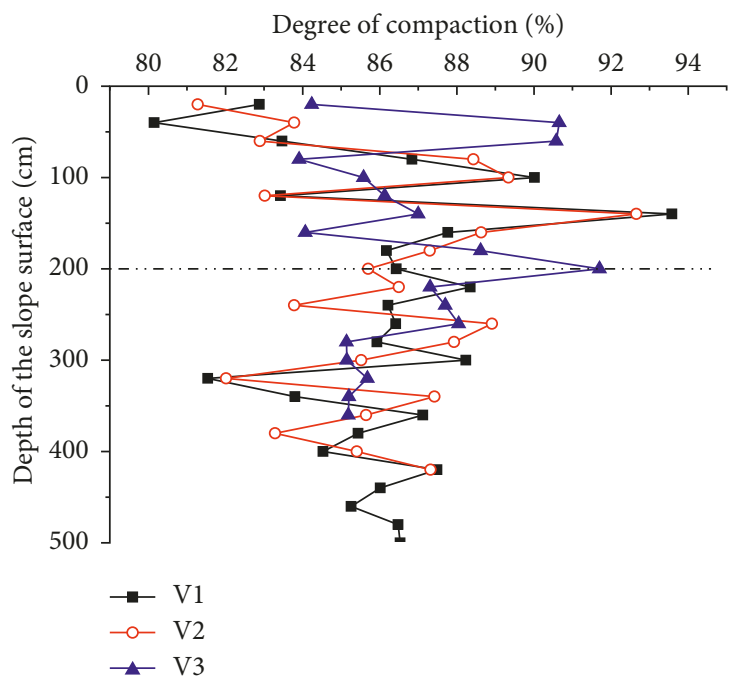

(b)

Figure 7: Water contents (a) and degrees of compaction (b) for the existing subgrade.

measured water contents, they are shown in Figure 10. It can be seen from Figure 10 that the estimated degrees of compaction of the subgrade based on the numerical water content, in general, do not deviate from the measured values significantly. Due to the inhomogeneity of the subgrade and the measured errors, some test points are scattered. Besides three discrete points, the root mean square errors between the estimated and measured degrees of compaction are $2.80 \%, 3.53 \%$, and $2.46 \%$ for V1, V2, and V3 sections, respectively, and their average value is $2.93 \%$. It shows that, for an existing subgrade, these degrees of compaction estimated by (1) according to the numerical and measured water contents are almost equivalent. Since the water content of any depth in subgrades can be determined using the numerical method in this study without excavating the subgrade slopes, which is much more timesaving than the measurement in the field, the PR and numerical water content can be used to predict the degree of compaction using (1) quickly. 


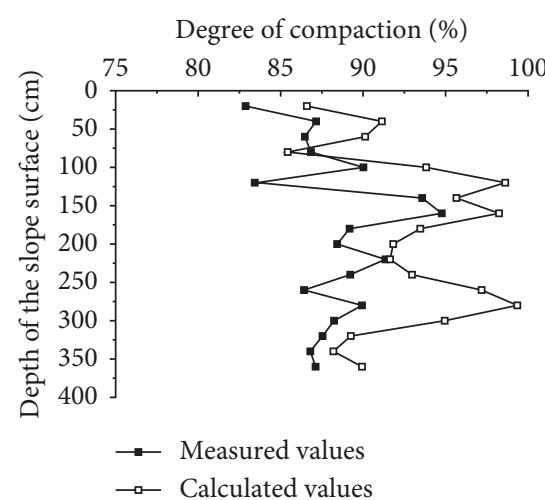

(a)

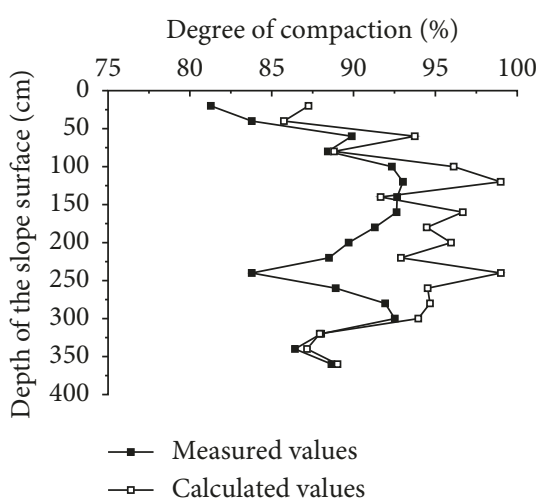

(b)

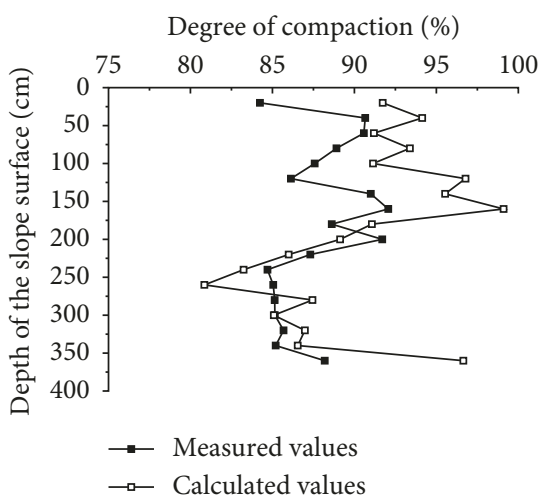

(c)

Figure 8: Estimated and measured degrees of compaction. Comparison of section: (a) V1; (b) V2; (c) V3.

TABLE 1: Parameters required for the numerical simulation [22].

\begin{tabular}{|c|c|c|c|}
\hline Parameter category & Relevant parameter & Symbol & Unit \\
\hline Hydraulic properties & $\begin{array}{l}\text { Soil-water characteristic curve } \\
\text { Saturated infiltration coefficient }\end{array}$ & $\begin{array}{c}\text { SWCC } \\
k_{\mathrm{ws}}\end{array}$ & $\overline{\mathrm{m} / \mathrm{s}}$ \\
\hline Thermodynamic properties & $\begin{array}{l}\text { Heat conductivity coefficient } \\
\text { Specific heat per unit volume }\end{array}$ & $\begin{array}{l}\lambda_{\mathrm{t}} \\
\lambda_{\mathrm{v}} \\
\end{array}$ & $\mathrm{J} /\left(\mathrm{m}^{3} \cdot{ }^{\circ} \mathrm{C}\right)$ \\
\hline Physiological parameters of vegetations & $\begin{array}{c}\text { Leaf area index } \\
\text { Root depth index }\end{array}$ & $\begin{array}{c}\text { LAI } \\
D_{\mathrm{R}} \\
\end{array}$ & $\overline{\mathrm{M}}$ \\
\hline Meteorological parameters & $\begin{array}{l}\text { Daily average temperature } \\
\text { Daily relative moisture } \\
\text { Daily relative wind speed } \\
\text { Daily average rainfall }\end{array}$ & $\begin{array}{c}T \\
\mathrm{RH} \\
U \\
P_{\mathrm{r}} \\
\end{array}$ & $\begin{array}{l}{ }^{\circ} \mathrm{C} \\
\% \\
\mathrm{~m} / \mathrm{s} \\
\mathrm{mm}\end{array}$ \\
\hline
\end{tabular}

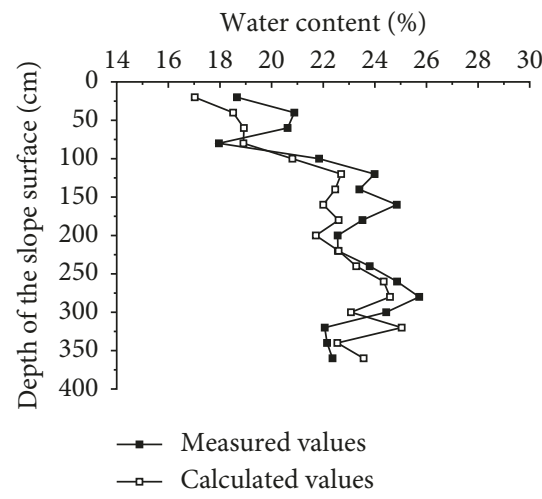

(a)

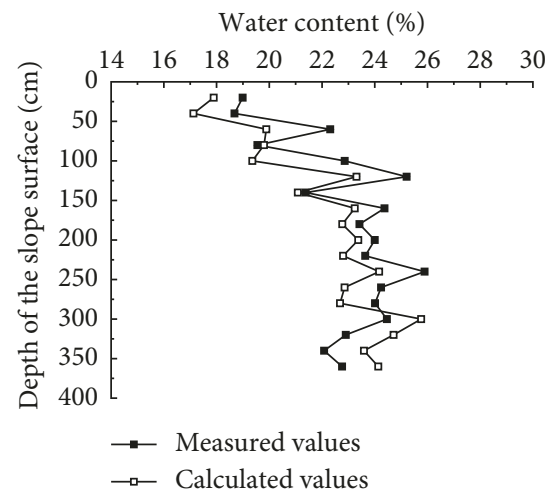

(b)

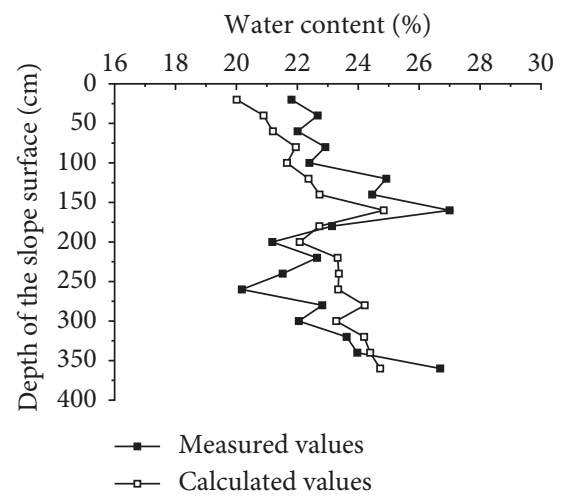

(c)

Figure 9: Calculated and measured water content values of soil at each vertical section. Comparison of vertical section: (a) V1; (b) V2; (c) V3.

\section{Conclusions}

The compaction test and light dynamic penetrometer (LDP) tests were carried out for low liquid-limit clay samples with different water contents in laboratory. The water content and degree of compaction were measured for a typical subgrade slope of $\mathrm{K} 24+600$ by the LDP test in field. Then, a prediction equation of the penetration ratio $(\mathrm{PR})$, degree of compaction $(K)$, and water content $(\omega)$ was built and verified. In order to avoid excavating the subgrade slope to measure its water content, a numerical method to determine the water content of a subgrade slope was put forward. It can be utilized to substitute the measured water content. Some major conclusions may be drawn as follows:

(1) A quadratic function between the degree of compaction, PR, and water content measured of low liquid-limit clay was established and verified. The root mean square error between the estimated and 


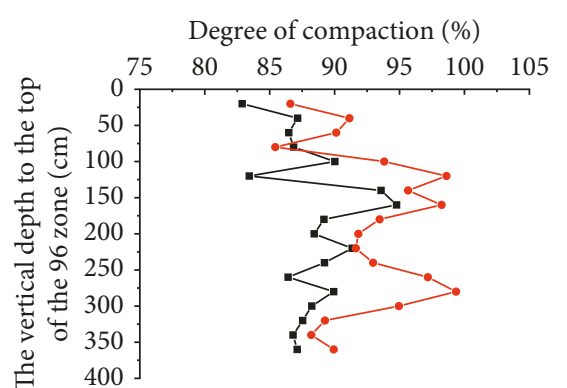

- - Measured value of V1 section
-- Calculated value of V1 section

(a)

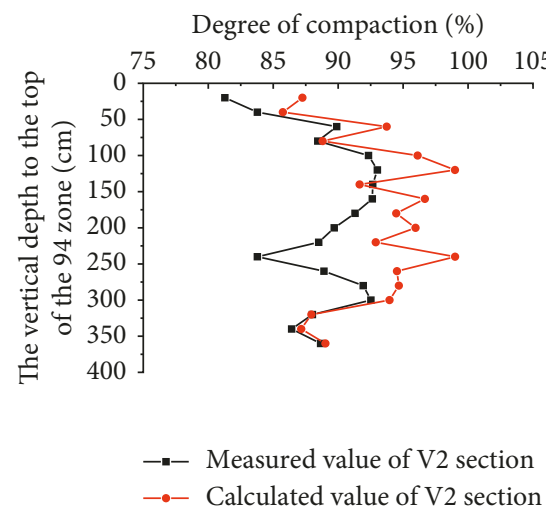

(b)

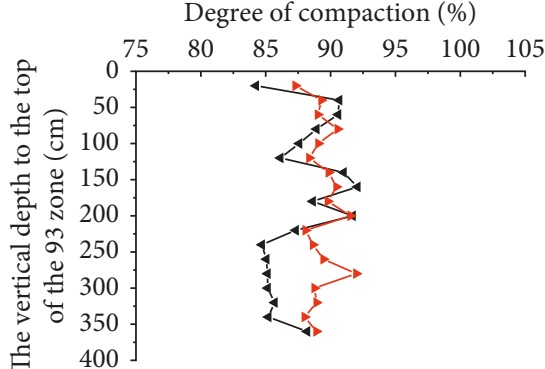

$\rightarrow-$ Measured value of $\mathrm{V} 3$ section
$\rightarrow-$ Calculated value of $\mathrm{V} 3$ section

(c)

FIGURE 10: Degrees of compaction calculated according to different water contents. Comparison of section: (a) V1; (b) V2; (c) V3.

measured degrees of compaction was within $3.5 \%$, which proves the validity of the relationship proposed in this study.

(2) It is difficult to measure the water content without excavating the subgrade slopes. A numerical method of water content for subgrade slope soils was proposed and verified. The results show that they have a relatively satisfactory accuracy. Therefore, this numerical method can be utilized to calculate the water content in subgrades, which is much more time saving than the on-site measurement.

(3) According to the numerical water content, the PR value obtained by the LDP-based field test, and the relationship between the degree of compaction, PR, and water content built in this study, the degree of compaction can be determined quickly. This method was proved to be rational by comparing the calculated and measured water contents.

\section{Data Availability}

The data used to support the findings of this study are available from the corresponding author upon request.

\section{Conflicts of Interest}

The authors declare that they have no conflicts of interest.

\section{Acknowledgments}

The authors gratefully acknowledge the financial support by the National Key Research and Development Program of China (2017YFC0805307), National Natural Science Foundation of China (51478054), Excellent Youth Foundation of Natural Science Foundation of Hunan Province (2018JJ1026), Key Project of Education Department of Hunan Province (17A008), Jiangxi Communications Department Program (2013C0011), and Open Research Fund of State Engineering Laboratory of Highway Maintenance Technology, Changsha University of Science and Technology (kfj150103).

\section{References}

[1] B. T. Nguyen and A. Mohajerani, "Determination of CBR for fine-grained soils using a dynamic lightweight cone penetrometer," International Journal of Pavement Engineering, vol. 16, no. 2, pp. 180-189, 2015.

[2] M. Kłos, Z. Waszczyszyn, and M. J. Sulewska, "Neural identification of compaction characteristics for granular soils," Nucleic Acids Research, vol. 30, no. 1, pp. 395-397, 2017.

[3] J. H. Zhang, J. H. Peng, J. L. Zheng, and Y. S. Yao, "Characterisation of stress and moisture dependent resilient behaviour for compacted clays in South China," Road Materials and Pavement Design, pp. 1-14, 2018.

[4] A. U. Rehman, K. Farooq, H. Mujtaba et al., "Prediction of California bearing ratio (CBR) and compaction characteristics of granular soils," Acta Geotechnica Slovenica, vol. 14, no. 1, pp. 63-72, 2017.

[5] A. M. Shaban and P. J. Cosentino, "Modeling long-term deformations of unbound pavement materials using the miniaturized pressure meter creep data," Geotechnical Testing Journal, vol. 39, no. 5, article 20150273, 2016.

[6] S. S. Park, "Evaluation of the sand-cone method for determination of the in-situ density of soil," Geotechnique, vol. 60, no. 9, pp. 701-707, 2010.

[7] J. W. Park and J. L. Ferracane, "Measuring the residual stress in dental composites using a ring slitting method," Dental Materials, vol. 21, no. 9, pp. 882-889, 2005.

[8] J. W. Park and J. L. Ferracane, "Evaluation of residual stress in self-adhesive resin cement by the thin ring cutting method," Dental Materials, vol. 27, no. S1, p. e58, 2011.

[9] G. Zhan, "Old and new embankment splicing technology in highway reconstruction project," Applied Mechanics and Materials, vol. 587-589, pp. 1190-1193, 2014.

[10] W. Liu, S. Qu, Z. Nie, and J. Zhang, "Effects of density and moisture variation on dynamic deformation properties of compacted lateritic soil," Advances in Materials Science and Engineering, vol. 2016, Article ID 5951832, 11 pages, 2016.

[11] J. H. Zhang, Q. P. Jiang, Y. Q. Zhang, L. L. Dai, and H. X. Wu, "Nondestructive measurement of water content and moisture migration of unsaturated red clays in South China," Advances in Materials Science and Engineering, vol. 2015, Article ID 542538, 7 pages, 2015.

[12] J. E. Herrick and T. L. Jones, "A dynamic cone penetrometer for measuring soil penetration resistance," Soil Science Society of America Journal, vol. 66, no. 4, pp. 1320-1324, 2002. 
[13] L. David Suits, T. C. Sheahan, D. H. Chen, D. F. Lin, P. H. Liau, and J. Bilyeu, "A correlation between dynamic cone penetrometer values and pavement layer moduli," Geotechnical Testing Journal, vol. 28, no. 1, pp. 42-49, 2005.

[14] S. A. Khedr, C. K. David, and L. James, "Automated cone penetrometer: a nondestructive field test for subgrade evaluation," International Journal of Rock Mechanics and Mining Sciences \& Geomechanics Abstracts, vol. 23, no. 3, p. 94, 1985.

[15] J. A. Siekmeier, D. Young, and D. Beberg, "Comparison of the dynamic cone penetrometer with other tests during subgrade and granular base characterization in Minnesota," in Nondestructive Testing of Pavements and Backcalculation of Moduli: Third Volume, ASTM International, West Conshohocken, PA, USA, 2000.

[16] V. George, N. C. Rao, and R. Shivashankar, "PFWD, DCP and CBR correlations for evaluation of lateritic subgrades," International Journal of Pavement Engineering, vol. 10, no. 3, pp. 189-199, 2009.

[17] J. N. Mukabi, "Review of DCP Based CBR-UCS and resilient modulus models for applications in highway and airport pavement design," US Army, vol. 10, p. 1, 2016.

[18] S. D. Mohammadi, M. R. Nikoudel, H. Rahimi, and M. Khamehchiyan, "Application of the dynamic cone penetrometer (DCP) for determination of the engineering parameters of sandy soils," Engineering Geology, vol. 101, no. 3-4, pp. 195-203, 2008.

[19] H. A. Alghamdi, Dynamic Cone Penetrometer (DCP) Based Evaluation of Sustainable Low Volume Road Rehabilitation Techniques, Ohio University, Columbus, OH, USA, 2016.

[20] U. Z. V. Emre, S. Mehmet, and İ. Gökalp, "Comparison of DCP, CBR, and RLT test results for granular pavement materials and subgrade with structural perspective," in Proceedings of the International Symposium Non-Destructive Testing in Civil Engineering (NDT-CE), vol. 2, pp. 158-176, Berlin, Germany, September 2015.

[21] B. Yang, R. Zhang, X. D. Zha, C. Liu, and Q. Pan, "Improved testing method of dynamic cone penetrometer in laboratory for evaluating compaction properties of soil subgrade," Road Materials and Pavement Design, vol. 17, no. 2, pp. 487-498, 2015.

[22] Y. S. Yao, J. L Zheng, Z. S. Chen, J. H. Zhang, and Y. Li, "Field measurements and numerical simulations of temperature and moisture in highway engineering using a frequency domain reflectometry sensor," Sensors, vol. 16, no. 6, p. 857, 2016.

[23] F. Niu, A. Li, J. Luo et al., "Soil moisture, ground temperatures, and deformation of a high-speed railway embankment in Northeast China," Cold Regions Science and Technology, vol. 133, pp. 7-14, 2017.

[24] N. An, S. Hemmati, and Y. Cui, "Numerical analysis of soil volumetric water content and temperature variations in an embankment due to soil-atmosphere interaction," Computers and Geotechnics, vol. 83, pp. 40-51, 2017.

[25] J. R. Philip and D. A. V. Deries, "Moisture movement in porous materials under temperature gradients," Transactions American Geophysical Union, vol. 38, no. 2, pp. 222-232, 1957.

[26] N. Lu, M. Kaya, and J. W. Godt, "Interrelations among the soilwater retention, hydraulic conductivity, and suction-stress characteristic curves," Journal of Geotechnical and Geoenvironmental Engineering, vol. 140, no. 5, article 04014007, 2014.

[27] C. W. W. Ng, C. Zhou, and A. K. Leung, "Comparisons of different suction control techniques by water retention curves: theoretical and experimental studies," Vadose Zone Journal, vol. 14, no. 9, 2015. 


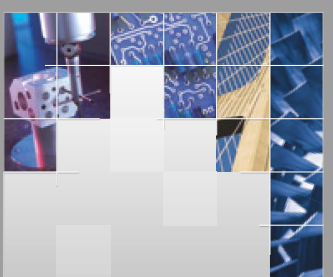

\section{Enfincering}
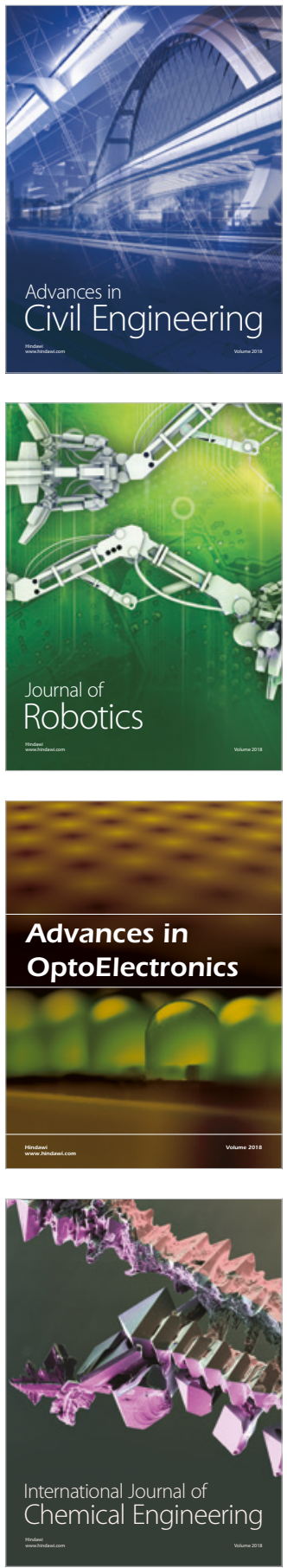

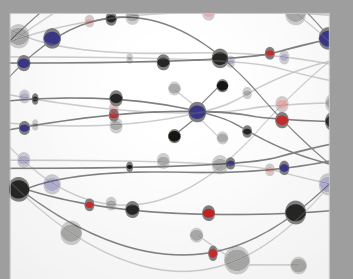

\section{Rotating \\ Machinery}

The Scientific World Journal

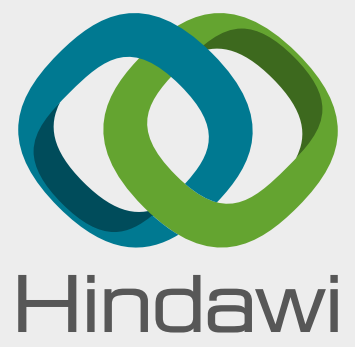

Submit your manuscripts at

www.hindawi.com
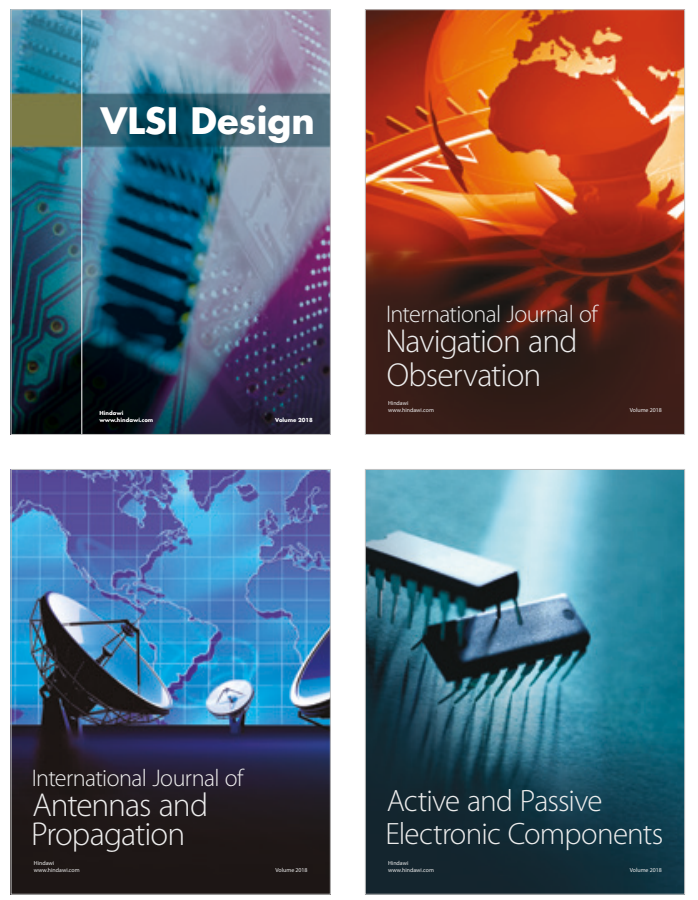
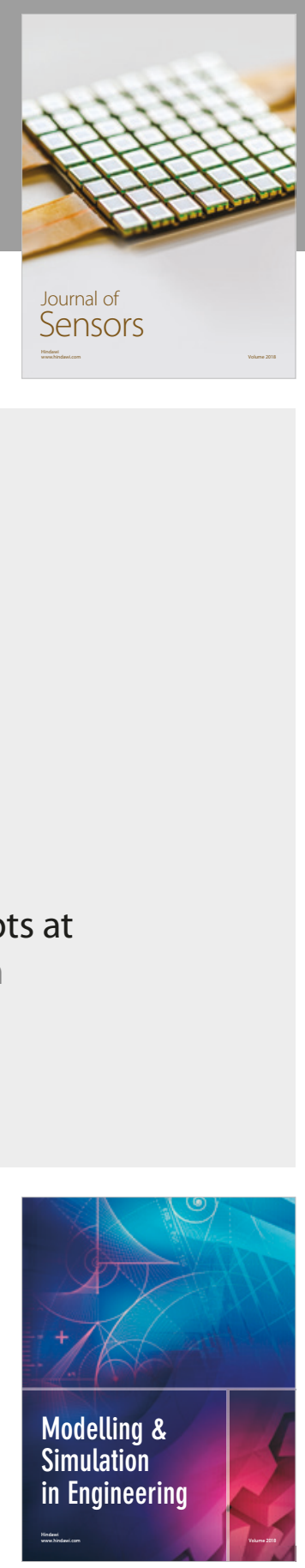

\section{Advances \\ Multimedia}
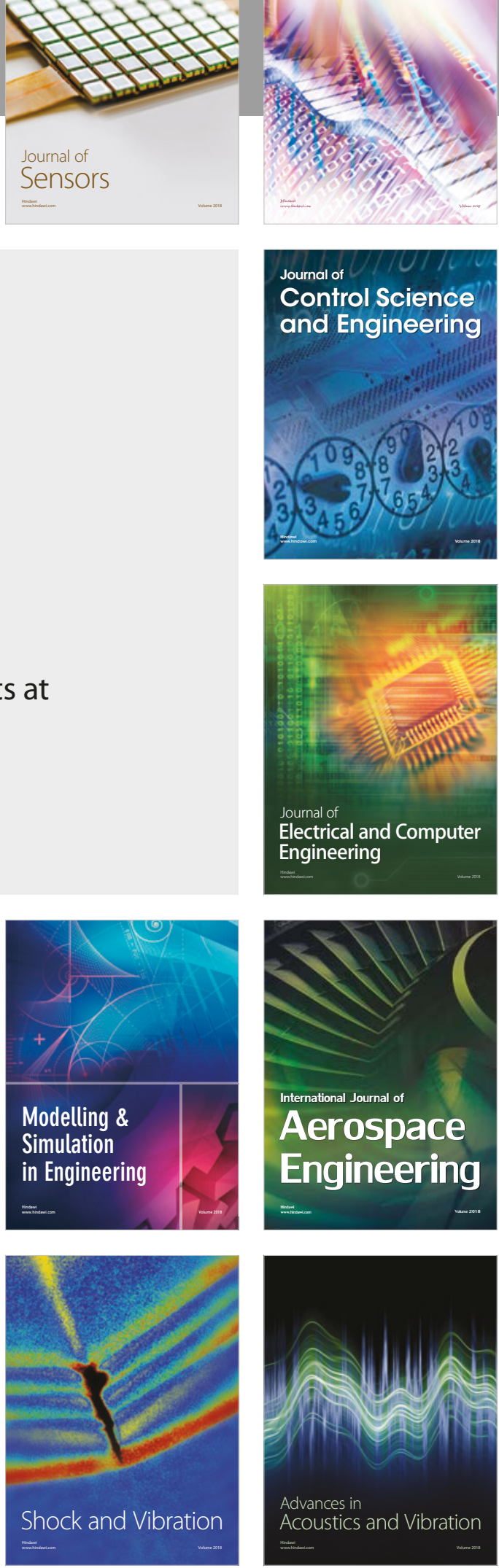